\title{
SÉNATUS-CONSULTE
}

\section{DE THISBÉ (170)}

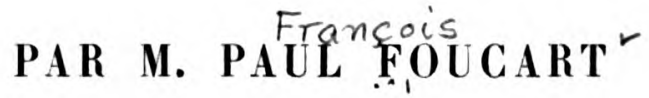

MEMBRE DE L'INSTITUT

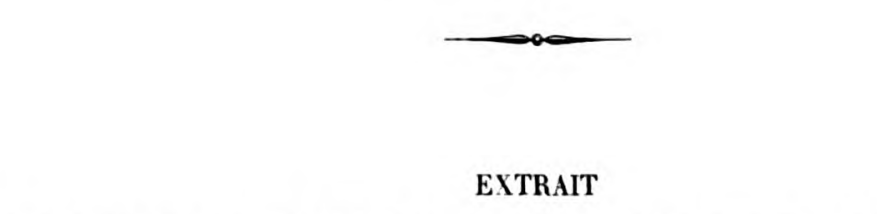

DES MÉMOIRES DE L'ACADÉMIE DES INSCRIPTIONS ET BELLES-LETTRES TOME XXXViI (2* PARTIE)

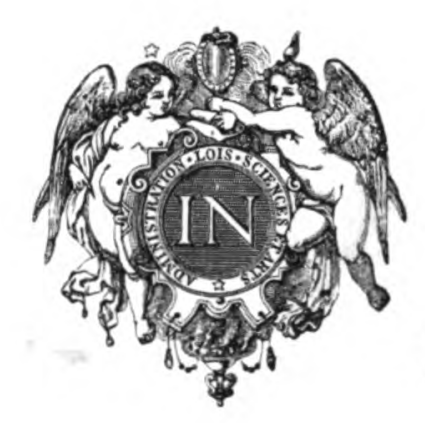

\section{PARIS}

\section{IMPRIMERIE NATIONALE}

LIBRAIRIE C. KLINCKSIECK, RUE DE LILLE, 11

MDCCCCV 